\title{
Probiotic potential of lyophilized Lactobacillus plantarum GP
}

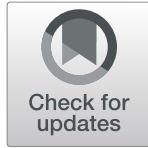

Satyamitra L. Shekh', Aarti A. Boricha², Jony G. Chavda ${ }^{2}$ and Bharatkumar Rajiv Manuel Vyas ${ }^{2 *}$ (D

\begin{abstract}
Purpose: Freeze drying of Lactobacillus plantarum GP in the presence of wall materials to achieve improved survival and retention of probiotic functionality during storage.

Methods: L. plantarum cells were lyophilized in the presence of inulin, fructooligosaccharides, lactulose, and/or skim milk. The lyophilized vials were stored at $8-10{ }^{\circ} \mathrm{C}$ up to 6 months and cells from these vials were evaluated for their probiotic functionality.

Results: L. plantarum GP freeze dried in the presence of wall material lactulose displayed viability of $98 \pm 2.8 \%$ promising survival rate in the stress conditions of human digestive tract. The freeze dried cells of Lactobacilli retained the ability to adhere intestinal mucin layer, form biofilm, inhibit food spoilage and enteropathogens, produce $\beta$-galactosidase, bile salt hydrolase and $\gamma$-amino butyric acid, remove cholesterol, and scavenge DPPH radical.

Conclusion: Lyophilized cells of L. plantarum GP retained all the functional characteristics without any significant loss during storage, which prompts to incorporate prebiotics for the development of stable functional food products.
\end{abstract}

Keywords: Lactobacillus plantrum, Synbiotics, Prebiotics, Antioxidative, Cholesterol reduction

\section{Introduction}

Probiotics are redefined as "live microorganisms that when administered in adequate amounts confer a health benefit on the host" (Hill et al. 2014). The rising interest and increasing demand by consumers for probiotics containing foods stimulated research related to this field since the year of 2000 (Jankovic et al. 2010). The strains characterized and used as probiotics belong to the group lactic acid bacteria (LAB). Several products including yogurt, cheese, ice cream, cereals, beverage powders, fruit juices, capsules, and chocolates have been developed and used as carriers for probiotic strains (Pavunc et al. 2011; Granato et al. 2015; Chavan et al. 2018; Konar et al. 2018). The dose and the viability of probiotic strains are important criteria for probiotic efficacy since the health benefits strongly depend on the viability of probiotic microorganisms. It has been suggested that a probiotic product should contain a minimum of $7 \log$

\footnotetext{
* Correspondence: brmvyas@hotmail.com

${ }^{2}$ Department of Biosciences, Saurashtra University, Rajkot 360005, India

Full list of author information is available at the end of the article
}

$\mathrm{cfu} / \mathrm{g}$ of viable cells at the time of consumption to confer health benefits (WHO 2006). However, a report has revealed lower survival rate of probiotics in traditional dairy products (de Vos et al. 2010). The poor survival of probiotics in probiotic products is attributed to processing conditions and environmental stress during storage such as $\mathrm{pH}$ and temperature variation as well as toxicity of oxygen and UV light. An adequate number of probiotic cells should retain the viability and functional properties during the storage and passage through stomach (Anal and Singh 2007).

The viability of probiotics may be increased by using prebiotics as prebiotics are resistant to gastric acidity, digestive enzymes of intestine, and environmental stress. Prebiotics have the potential in improving the stability and viability of $\mathrm{LAB}$ during processing, storage, and gastrointestinal tract transit (Burgain et al. 2011; Heidebach et al. 2012). Moreover, prebiotics also serve as fermentable carbohydrates for probiotic microorganisms in the colon (Gibson 1999). Hence, the combination of probiotic and prebiotics known as "synbiotics" is preferred 
as it selectively enhances the viable number of probiotic organisms (Gibson 1999; Gonzalez et al. 2011; Rodrigues et al. 2011). The selection of compounds is challenging as the variety of materials available in the market is huge. According to the guidelines (EAFUS 1998), the wall material should be of food grade as well as effective in protecting the probiotics. Compounds like sugar and skim milk also protect $\mathrm{LAB}$ during passage through the GIT and storage (Carvalho et al. 2004; Malik 1988). Besides this, material and lyophilization process should be compatible with the specific probiotic (de Vos et al. 2010). There are several methods, but not without limitations, like emulsification, coacervation, spray drying, and spray cooling to obtain dried viable cells which can be used in food products. Freeze drying therefore is a widely used method to produce dried viable LAB (Meng et al. 2008; Fonseca et al. 2015).

The objective of this work was to lyophilize the probiotic strain Lactobacillus plantarum GP isolated from grapes and to evaluate the changes in the probiotic efficacy upon lyophilization in the presence of different wall materials. The strain was selected on the basis of probiotic efficacy tested by various screening tests earlier (Shekh et al. 2016). Inulin, fructooligosaccharides and galactooligosaccharide (lactulose), skim milk powder, and sucrose were studied as wall materials to evaluate their influence on the stability and viability of probiotics during lyophilization and storage. The "synbiotics" were prepared by freeze drying and tested for survival in simulated oro-gastro-intestinal fluids, mucin adherence, biofilm formation ability, antibacterial activity, cholesterol removal, and antioxidant activity. The abovementioned probiotic properties were evaluated after the preparation of synbiotics and subsequently during the storage period of 6 months.

\section{Materials and methods}

Culture conditions and chemicals

Lactobacillus plantarum GP KF479387 (L. plantarum GP) isolated from grapes was grown on De Man Rogosa and Sharpe (MRS, pH 6.5) agar plates at $37{ }^{\circ} \mathrm{C}$ for $48 \mathrm{~h}$. Isolated colony was inoculated in 5-mL MRS medium and subcultured twice in the MRS medium. One milliliter of activated culture was inoculated in 50-mL MRS medium, incubated for $18 \mathrm{~h}$ at $37{ }^{\circ} \mathrm{C}$, and used for inoculating 1-L MRS medium for biomass production. Pure culture in MRS medium with $10 \%$ (v/v) glycerol was preserved at $-20{ }^{\circ} \mathrm{C}$. Lactobacillus rhamnosus was used as reference strain throughout the study and was grown in identical cultural conditions as L. plantarum GP. The test microorganisms Escherichia coli MTCC 1697, Enterobacter aerogenes MTCC 111, Salmonella typhi MTCC 98, Serratia marcescens MTCC 97, Shigella sp., Pseudomonas aeruginosa MTCC 2587, Proteus vulgaris, Klebsiella pneumoniae, and Bacillus spp., were grown at $37{ }^{\circ} \mathrm{C}$ in static condition in $10-\mathrm{mL}$ nutrient broth test tubes. Staphylococcus aureus MTCC 1144 was grown in test tube at $37{ }^{\circ} \mathrm{C}$ for $18 \mathrm{~h}$ in $10-\mathrm{mL}$ Brain Heart Infusion broth for antimicrobial assay.

Lactulose was purchased from Sigma (USA). Fructooligosaccharides, inulin, and all other chemicals, if not indicated otherwise, were purchased from Himedia (India).

\section{Capability to grow in the presence of prebiotics}

The growth of Lactobacillus plantarum GP and $L$. rhamnosus GG was screened on various prebiotics including inulin, fructooligosaccharides, and lactulose by agar plate assay as described by Kaplan and Hutkins (2000). Ten microliters of cell suspension prepared according to Shekh et al. (2016) from 18-h Lactobacillus cultures was spotted on MRS agar medium containing the prebiotics as carbon source $(1 \% \mathrm{w} / \mathrm{v})$ and $300-\mathrm{mg} / \mathrm{L}$ bromocresol purple as a color indicator and incubated at $37{ }^{\circ} \mathrm{C}$ for $48 \mathrm{~h}$. A color change around the developing colonies from purple to yellow was recorded.

\section{Preparation of lyophilized cells}

The cells were harvested from $1 \mathrm{~L}$ of $24 \mathrm{~h}$ culture of $L$. plantarum GP and L. rhamnosus GG grown (at $37{ }^{\circ} \mathrm{C}$ in static condition) in MRS medium by centrifugation $\left(5000 \times \mathrm{g}, 20 \mathrm{~min}, 4{ }^{\circ} \mathrm{C}\right)$. Cell pellet $(1 \mathrm{~g})$ was washed thrice with distilled water $(\mathrm{D} / \mathrm{W})$ to remove medium components and mixed with $1 \mathrm{~g}$ of wall material (1:1, cells:prebiotics/sucrose). $0.5 \mathrm{~g}$ of skim milk was added to another set of cryovials as cryoprotective agent in addition to $0.5 \mathrm{~g}$ of wall materials (2:1:1; cells:prebiotics/ sucrose:skim milk; Table 1). Control contained cells without any wall material or skim milk. $300-\mu \mathrm{L}$ aqueous solution $\left(20 \times 10^{9} \mathrm{cfu}\right)$ from the abovementioned

Table 1 Viability (\%) of Lactobacillus plantarum GP and Lactobacillus rhamnosus GG cells lyophilized in the presence of wall materials

\begin{tabular}{lll}
\hline Wall materials & \multicolumn{2}{l}{ Viability (\%) } \\
\cline { 2 - 3 } & L. plantarum GP & L. rhamnosus GG \\
\hline Control & $75 \pm 1.5$ & $58 \pm 3.8$ \\
Fructooligosaccharide & $90 \pm 0.9$ & $77 \pm 0.6$ \\
Inulin & $90 \pm 2.1$ & $76 \pm 2.0$ \\
Lactulose & $98 \pm 0.4^{*}$ & $60 \pm 1.0$ \\
Sucrose & $95 \pm 0.6^{*}$ & $75 \pm 3.1$ \\
Fructooligosaccharide + skim milk & $83 \pm 4.3$ & $80 \pm 1.4$ \\
Inulin + skim milk & $91 \pm 1.1$ & $74 \pm 2.0$ \\
Lactulose + skim milk & $90 \pm 2.5$ & $89 \pm 2.6^{*}$ \\
Sucrose + skim milk & $83 \pm 1.5$ & $89 \pm 0.9^{*}$ \\
Skim milk & $68 \pm 3.6$ & $75 \pm 1.2$ \\
\hline
\end{tabular}

${ }^{*}$ values significantly different $(P<0.05)$ 
Eppendorf was distributed in cryovials, frozen at $-20{ }^{\circ} \mathrm{C}$ for $18 \mathrm{~h}$, and lyophilized using Micromodulyo 0230 (ThermoScientific, USA; $-50{ }^{\circ} \mathrm{C}, 8 \mathrm{~h}, 3.8 \times 10^{-2}$ Torr). Lyophilized vials stored up to 6 months at $8-10{ }^{\circ} \mathrm{C}$ were evaluated for their probiotic properties and lyophilized cells with different wall materials were observed by scanning electron microscopy.

\section{Enumeration of bacteria and percentage of viability}

Lyophilized cells were uniformly suspended in $300 \mu \mathrm{L}$ of phosphate buffer saline (PBS-pH 7, $0.1 \mathrm{M} ; 0.85 \% \mathrm{NaCl}$ ) according to Rajam et al. (2012). Aliquots from the samples $(0.1 \mathrm{~mL})$ diluted in $\mathrm{N}$-saline $(0.85 \% \mathrm{NaCl})$ were pour plated on MRS agar and incubated at $37{ }^{\circ} \mathrm{C}$ for 48 $\mathrm{h}$. All the enumerations were performed in duplicate and plates containing 20 to 350 colonies were considered for determining viable cell count $(\log \mathrm{cfu} / \mathrm{mL})$. The number of viable cells from the vials before $\left(N_{0}\right)$ and after lyophilization $(N)$ was evaluated and expressed as viability $(\%):\left(N / N_{0}\right) \times 100$

\section{Scanning electron microscopy of lyophilized cells}

Lyophilized powders of Lactobacilli were fixed to a sample slide using conductivity adhesive tape and subjected to $10 \mathrm{~mA}$ process current for $2 \mathrm{~min}$ (Sputter Coater, SC7620, Emitech) to achieve gold coating. The morphology of gold-coated samples was observed by scanning electron microscopy at $10.0 \mathrm{kv}$ (Zeiss, EVO-18).

\section{Probiotic properties}

\section{Survival of lyophilized cells in oro-gastro-intestinal fluids}

Simulated saliva (SS), simulated gastric fluid (SGF), and simulated intestinal fluid (SIF) were prepared as in our previous reports (Pithva et al. 2014; Shekh et al. 2016) to mimic the transit of lyophilized cells in human oral and gastrointestinal cavities. Fifteen microliters of cell suspension $\left(10^{9}\right.$ cells $)$ prepared from lyophilized vials as above was incubated in 1-mL SS, SGF, and SIF for 10, 120 , and $180 \mathrm{~min}$ respectively. The viable number of cells after each fluid transit, i.e., SS, SS-SGF, and SSSGF-SIF was measured by plating appropriate dilution on molten MRS agar and cell viability was expressed as $\log \mathrm{cfu} / \mathrm{mL}$.

\section{Mucin adherence}

The adhesive capacity of lyophilized cells to intestinal mucin layer was evaluated according to Dhanani and Bagchi (2013) in 96-well microtiter plate coated with porcine stomach type III mucin (Sigma). Briefly, $300 \mu \mathrm{L}$ of mucin $(0.5 \mathrm{mg} / \mathrm{mL})$ in sterile Dulbecco's PBS (Sigma) was added in microtiter plate well and held at $4{ }^{\circ} \mathrm{C}$ overnight for mucin coating. Wells were washed thrice with PBS to remove unbound mucin. Fifteen microliters of cell suspension was then added to the well and final volume was adjusted to $200 \mu \mathrm{L}$ with PBS and held at 37 ${ }^{\circ} \mathrm{C}$ to allow adherence of cells to mucin layer for $90 \mathrm{~min}$. Unbound cells were withdrawn and wells were washed five times with PBS. Adhered cells were extracted using $300 \mu \mathrm{L}$ of Triton $\mathrm{X}-100(0.05 \% \mathrm{v} / \mathrm{v}$, prepared in sterile PBS) for $20 \mathrm{~min}$ at $37{ }^{\circ} \mathrm{C}$. The adhered cells were counted by plating appropriate dilution on MRS agar.

\section{Biofilm formation}

Sterile 96-well round bottom microtiter plate was filled with $200-\mu \mathrm{L}$ MRS broth per well. Fifteen microliters cell suspension was added to the well and incubated at $37{ }^{\circ} \mathrm{C}$ for $72 \mathrm{~h}$ without agitation. Unbound bacterial cells were removed by washing plates thrice with sterile PBS and surface attached bacterial cells were stained with $0.1 \%$ $(\mathrm{w} / \mathrm{v})$ crystal violet in isopropanol-methanol-PBS (1:1:18) for 30 min (Watnick and Kolter 1999; Nilsson et al. 2008). Excess dye was removed by washing wells three times with PBS. The residual dye bound to the surface adhered cells was extracted with $200 \mu \mathrm{L}$ of dimethyl sulphoxide and estimated by measuring $\mathrm{A}_{570}$ using microtiter plate reader (BioTek, $\mu$ Quant, USA). The amount of crystal violet $(\mu \mathrm{g})$ bound to the surface of microtiter plate wells was determined using the standard curve of crystal violet.

\section{Antibacterial activity}

The antibacterial action of Lactobacillus cells against food spoiling and/or human pathogens was determined by spot inoculation method (Schillinger and Lucke 1989) with minor modification. In brief, $2 \mu \mathrm{L}$ of cell suspension was spotted on MRS agar plate and incubated for $24 \mathrm{~h}$ at $37{ }^{\circ} \mathrm{C}$. Further, $100 \mu \mathrm{L}$ of test pathogen was mixed with $10 \mathrm{~mL}$ of nutrient or BHI agar (1\%) and overlaid on previously spot inoculated MRS agar plates with Lactobacilli cells and incubated at $37^{\circ} \mathrm{C}$ for $24 \mathrm{~h}$.

\section{Deconjugation of sodium taurocholate and sodium glycocholate}

Ten milliliters volumes of MRS broth supplemented with $0.2 \%(\mathrm{w} / \mathrm{v})$ sodium glycocholate (Sigma) and $0.2 \%$ $(\mathrm{w} / \mathrm{v})$ sodium taurocholate (Sigma) were inoculated with $15-\mu \mathrm{L}$ cell suspension from each lyophilized capsule. Tubes were incubated aerobically at $37^{\circ} \mathrm{C}$ for $19 \mathrm{~h}$ and analyzed for the release of free cholic acid in the medium according to Irvin et al. (1944) as modified by Walker and Gilliland (1993). Briefly, 10-mL culture of each strain after the incubation period was adjusted to $\mathrm{pH} 7.0$ with $1 \mathrm{M} \mathrm{NaOH}$ and centrifuged $\left(10,000 \times g, 4{ }^{\circ} \mathrm{C}\right.$, $10 \mathrm{~min})$. The supernatant was transferred into a clean test tube, $\mathrm{pH}$ adjusted to 1.0 with $10 \mathrm{M} \mathrm{HCl}$, and centrifuged $\left(10,000 \times g, 4{ }^{\circ} \mathrm{C}, 10 \mathrm{~min}\right)$. One milliliter of supernatant was mixed with $2 \mathrm{~mL}$ of ethyl acetate, vortexed for $1 \mathrm{~min}$, and then the phases were allowed to separate. 
Two milliliters of the ethyl acetate layer was transferred to a clean test tube and evaporated to dryness at $60{ }^{\circ} \mathrm{C}$ in a water bath. The residues were immediately dissolved in $1 \mathrm{~mL}$ of $10 \mathrm{mM} \mathrm{NaOH}$ and mixed with $1 \mathrm{~mL}$ of $1 \%$ (w/v) furfuraldehyde (Sigma) and $1 \mathrm{~mL}$ of $8 \mathrm{M} \mathrm{H}_{2} \mathrm{SO}_{4}$. The reaction mixture was vortexed for $1 \mathrm{~min}$ and held at $65{ }^{\circ} \mathrm{C}$ in a water bath for $10 \mathrm{~min}$. The test tubes were cooled to room temperature, $2 \mathrm{~mL}$ of glacial acetic acid was added, the mixture was vortexed for $1 \mathrm{~min}$, and $\mathrm{A}_{660}$ was measured. The amount of cholic acid released was determined using cholic acid standard.

\section{Cholesterol removal assay}

Ten-milliliter MRS broth containing cholesterol (100 $\mu \mathrm{g} / \mathrm{mL}$ ) was inoculated with $15 \mu \mathrm{L}$ of cell suspension prepared from lyophilized cells, incubated at $37{ }^{\circ} \mathrm{C}$ for $24 \mathrm{~h}$, centrifuged $\left(10,000 \times g, 4{ }^{\circ} \mathrm{C}, 10 \mathrm{~min}\right)$, and cholesterol concentration in the supernatant was determined according to Gilliland et al. (1985). $0.5 \mathrm{~mL}$ of supernatant and $3 \mathrm{~mL}$ of $95 \%$ ethanol were mixed and vortexed for $1 \mathrm{~min}$. Two milliliters of $50 \%$ (w/v) $\mathrm{KOH}$ was added to the tubes, vortexed for $1 \mathrm{~min}$, held at $65{ }^{\circ} \mathrm{C}$ in water bath for $10 \mathrm{~min}$, cooled to room temperature, followed by the addition of $5-\mathrm{mL}$ hexane and $3-\mathrm{mL}$ distilled water, vortexed for $1 \mathrm{~min}$, and the phases were allowed to separate. $2.5 \mathrm{~mL}$ of hexane layer was transferred to a clean test tube and evaporated to dryness at $60{ }^{\circ} \mathrm{C}$ in a water bath. The residues were then dissolved in 4-mL o-phthalaldehyde reagent, vortexed for $1 \mathrm{~min}$, and held at room temperature for $10 \mathrm{~min}$. Two milliliters of concentrated sulfuric acid was added to the mixture and vortexed for $1 \mathrm{~min}$. $\mathrm{A}_{550}$ was measured to determine cholesterol using cholesterol standard. MRS with cholesterol $(100 \mu \mathrm{g} / \mathrm{mL})$ was used as a control. Percentage of cholesterol removed was calculated as $(A)=$ $\left[\left(A_{\mathrm{b}}-A_{\mathrm{c}}\right) / A_{\mathrm{b}}\right] \times 100$, where $A_{\mathrm{b}}=$ absorbance of blank and $A_{\mathrm{c}}=$ absorbance of cell supernatant.

\section{$\beta$-galactosidase activity}

Fifteen microliters of cell suspension $\left(10^{9}\right.$ cells $)$ prepared from lyophilized vials was mixed with $2.7 \mathrm{~mL}$ of permeabilization buffer containing g/L of $16.1 \mathrm{Na}_{2} \mathrm{H}$ $\mathrm{PO}_{4} \cdot 2 \mathrm{H}_{2} \mathrm{O}, \quad 5.5 \quad \mathrm{NaH}_{2} \mathrm{PO}_{4} \cdot 2 \mathrm{H}_{2} \mathrm{O}, \quad 0.75 \mathrm{KCl}, \quad 0.25$ $\mathrm{MgSO}_{4} \cdot 7 \mathrm{H}_{2} \mathrm{O}, 1.0$ sodium dodecyl sulfate, $2.7 \mathrm{~mL} \beta$ mercaptoethanol, and held at $37{ }^{\circ} \mathrm{C}$ for $30 \mathrm{~min}$. After incubation, $0.6 \mathrm{~mL}$ of $o$-nitrophenyl- $\beta$-D-galactopyranosidase $(4 \mathrm{mg} / \mathrm{mL})$ was mixed and after the appearance of yellow color the reaction was terminated by adding 2 $\mathrm{mL}$ of chilled $1 \mathrm{M} \mathrm{Na}_{2} \mathrm{CO}_{3}$ solution. $\mathrm{A}_{420}$ was measured and the activity in the presence of lactose (Miller's unit) was determined using the formula $\left(\left(A_{\mathrm{c}}-A_{\mathrm{b}} / t\right) \times 1000\right)$, where $A_{\mathrm{c}}$ is absorbance of lyophilized cells, $A_{\mathrm{b}}$ is absorbance of blank, and $t$ is time in min.

\section{DPPH scavenging activity}

The DPPH radical scavenging activity of lyophilized cells was evaluated by the method of Shimada et al. (1992) with minor modifications. Fifteen microliters of cell suspension and $1.0 \mathrm{~mL}$ of freshly prepared $0.2 \mathrm{mM} \mathrm{DPPH}$ solution (in methanol) were mixed and allowed to react for 30 min in dark. PBS was used as blank and DPPH scavenging ability was expressed as percentage of scavenging ability: $\left(A_{\mathrm{b}}-A_{\mathrm{t}} / A_{\mathrm{b}}\right) \times 100$ by measuring decrease in $\mathrm{A}_{517}$, where $A_{\mathrm{t}}=$ absorbance of test and $A_{\mathrm{b}}=$ absorbance of blank.

\section{GABA production}

Lactobacillus strains were grown in MRS medium containing monosodium glutamate $(5 \% \mathrm{w} / \mathrm{v})$ at $37{ }^{\circ} \mathrm{C}$ for 72 h. The cell-free supernatant that was obtained upon centrifugation $\left(10,000 \times g, 4{ }^{\circ} \mathrm{C}, 10 \mathrm{~min}\right)$ was passed through a syringe filter $(0.45 \mu \mathrm{m})$. GABA present in cell-free supernatant was separated and identified by TLC on activated silica gel plates (Silica gel $60 \mathrm{~F}_{254}$, Merck) as in the method of Lee et al. (2010).

\section{Statistical analysis}

All experiments were performed in triplicate and repeated at least once and the data of representative experiment are presented as mean $\pm \mathrm{SD}$ of the data. Statistical significance $\left(^{*}\right)$ and analysis of variance (ANOVA) were determined using Microsoft Excel 2010 at $P<0.05$.

\section{Results}

\section{Prebiotic utilization by agar plate assay}

Lactobacillus plantarum GP utilized the three prebiotics as indicated by the appearance of yellow zone against a purple background on MRS agar plates indicating acid production. Lactobacillus rhamnosus GG did not utilize any of the prebiotics used in the study.

\section{Viability (\%) after lyophilization}

The percentage of viability of $L$. plantarum GP and $L$. rhamnosus GG with or without wall materials is shown in Table 1. GP displayed higher viability with prebiotic lactulose and sugar sucrose by $\geq 95 \%$. GG lyophilized with lactulose and sucrose in combination with skim milk exhibited $89 \%$ viability which was $58 \%$ in control. Scanning electron micrograph of GP (Fig. 1i, ii) with lactulose and sucrose indicated coating of cells with smooth matrix of wall materials. The rough and porous freeze-dried powders obtained by lyophilizing GG with skim milk and sucrose + skim milk (Fig. 1iii, iv) showed the presence of long filamentous cellular structures with matrices in scanning electron micrographs. 


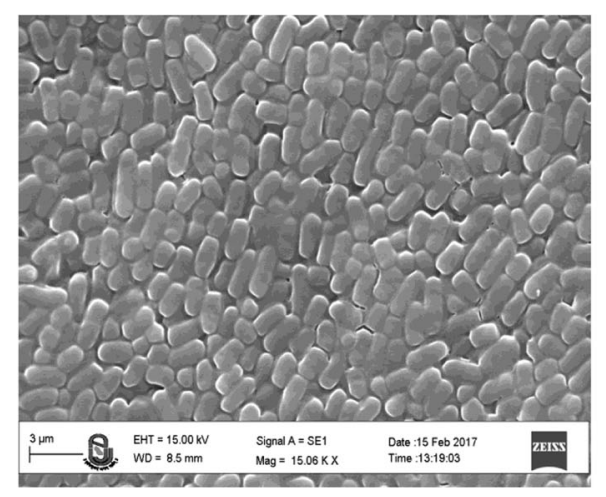

(i)

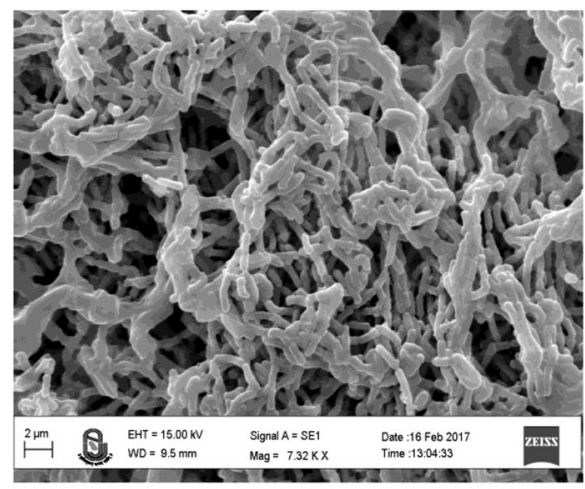

(iii)

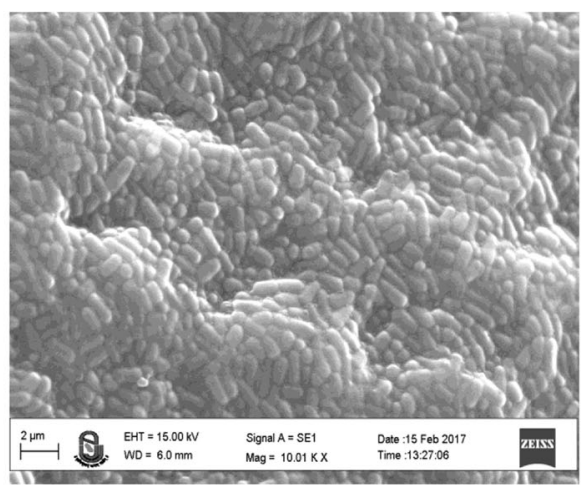

(ii)

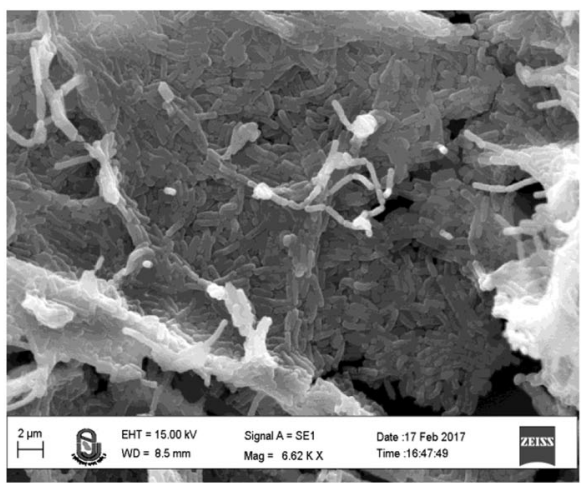

(iv)

Fig. 1 Scanning electron micrographs of lyophilized cells of Lactobacillus plantarum GP with i lactulose, ii sucrose and Lactobacillus rhamnosus GG, iii lactulose + skim milk, and iv skim milk

\section{Survival of lyophilized cells in oro-gastro-intestinal fluids} The survival of lyophilized cells of Lactobacilli after sequential exposure to simulated saliva (SS), simulated gastric fluid (SGF), and simulated intestinal fluid (SIF) was evaluated to determine their viability during orogastro-intestinal transit. The Lactobacillus strains stored for 2 months retained $\geq 88,66$, and $45 \%$ viability after subsequent exposure to SS, SS-SFG, and SS-SGF-SIF and an average reduction of $0.8,2.0$, and $3.2 \mathrm{log}$ cycle was observed after exposure to SS, SS-SFG, and SS-SGFSIF respectively. The lyophilized cells after 4 months of storage displayed $\geq 70,45$, and $30 \%$ viability during SS, SS-SGF, and SS-SGF-SIF transit respectively. The survival of lyophilized cells after 6 months of storage was $\geq$ 60,44 , and $28 \%$ in SS, SS-SGF, and SS-SGF-SIF respectively (Fig. 2). Among all the vials, GP lyophilized with lactulose displayed significantly higher survival rate after 2,4 , and 6 months storage period.

\section{Mucin adherence}

L. plantarum GP and L. rhamnosus GG cells lyophilized in the presence of prebiotic, sucrose, and/or skim milk exhibited different mucin adhesion capacity (Fig. 3).
Lyophilized vials stored for 2 months retained significant mucin adhesion capacity (4.4 to $6.8 \mathrm{log}$ cfu/well) in comparison with normally grown cells as reported previously (Shekh et al. 2016). Mucin adhesion capacity of lyophilized cells after 4 and 6 months of storage was in the range of 3.1 to $5.7 \log \mathrm{cfu} /$ well and 2.04 to $4.26 \log \mathrm{cfu} /$ well respectively.

\section{Biofilm formation}

The ability to form biofilm was considerably enhanced in L. plantarum GP and L. rhamnosus GG lyophilized with different wall materials as compared with cells lyophilized without any wall material. The experiment was carried out to determine the ability to form biofilm on the basis of crystal violet bound to biofilms produced by lyophilized cells after 2, 4, and 6 months storage (Fig. 4). The crystal violet binding was higher in GG + sucrose + skim milk ranging from $1.15,0.81$, and $0.39 \mu \mathrm{g}$ after 2,4 , and 6 months of storage respectively.

\section{Antimicrobial activity}

Lyophilized cells exerted antimicrobial activity against selected test pathogens (Table 2). The extent of 


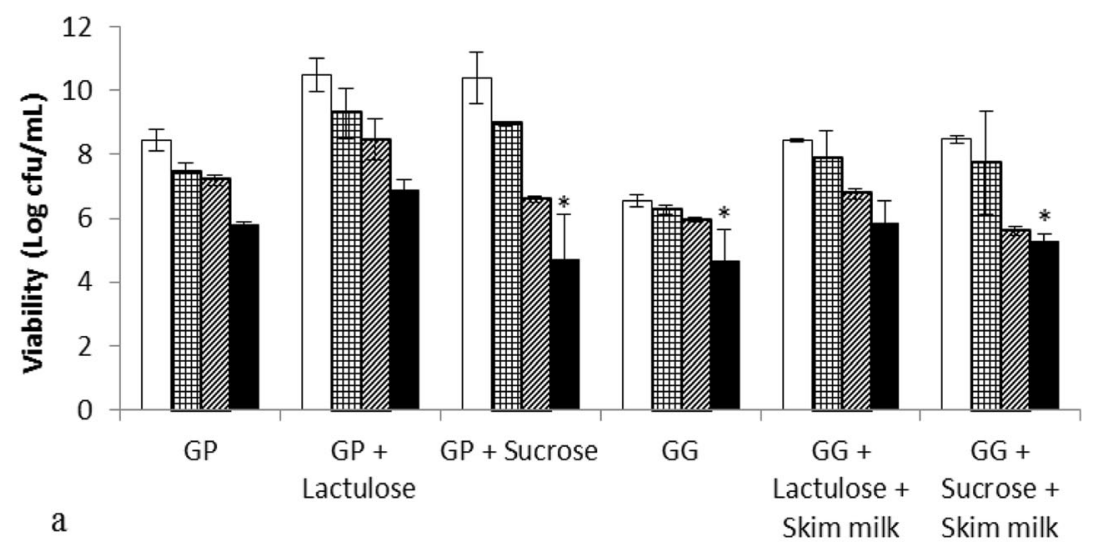

(a)

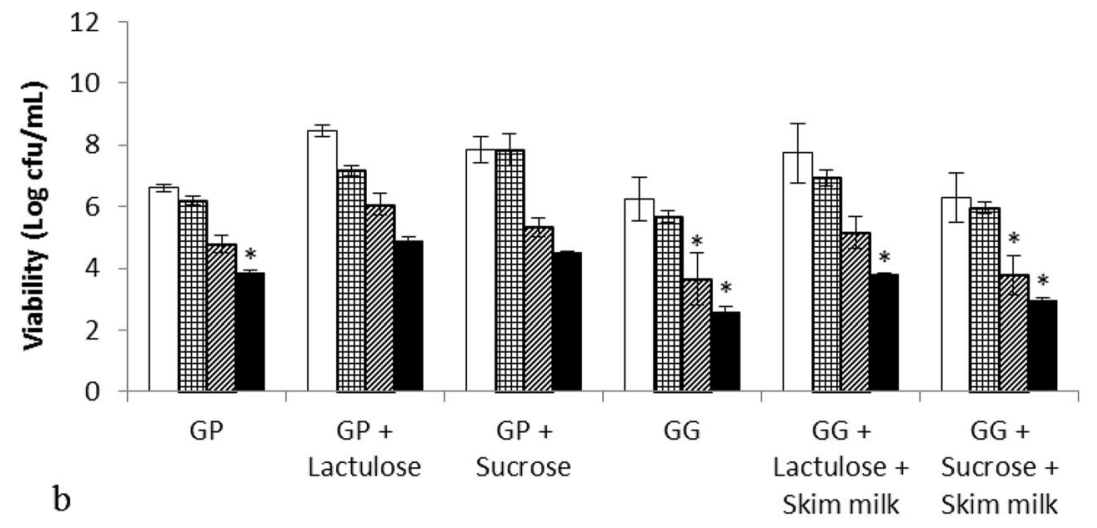

(b)

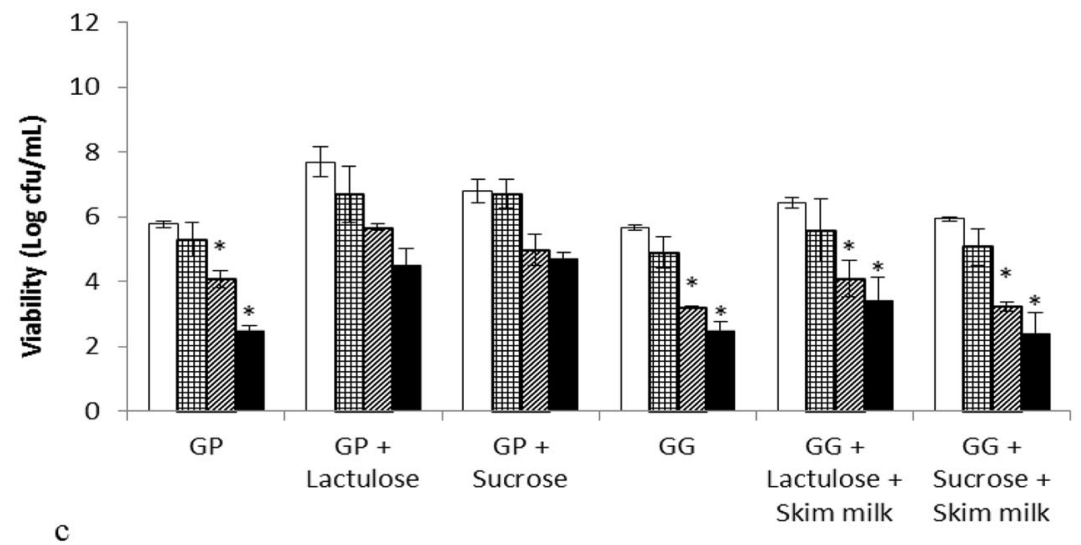

(c)

Fig. 2 Survival (log cfu/mL) of lyophilized Lactobacillus rhamnosus GG and Lactobacillus plantarum GP cells stored at $8-10{ }^{\circ} \mathrm{C}$ for $\mathbf{a} 2, \mathbf{b} 4$, and $\mathbf{c} 6$ months ( $\square$, control) upon sequential exposure to SS $(\mathbb{\boxplus})$, SS-SGF $(\mathbb{Z})$, and SS-SGF-SIF $(\boldsymbol{\square})$ determined by viable count method on MRS medium. *significantly different $(P<0.05)$ 


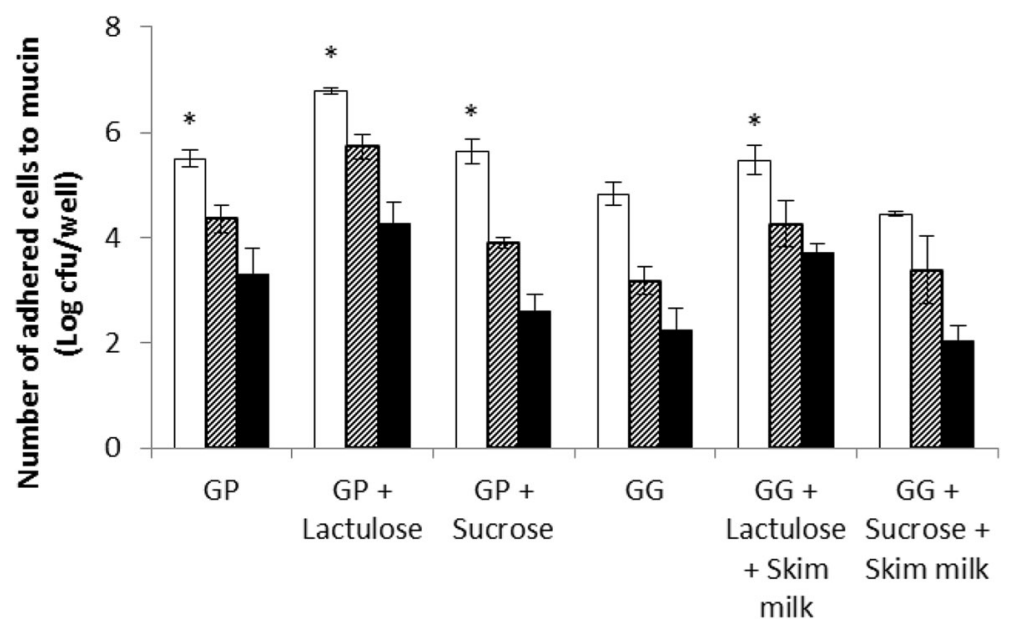

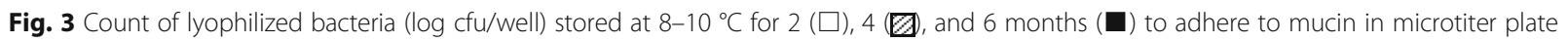
determined by viable count method using MRS medium after. ${ }^{*}$ significantly different $(P<0.05)$

antimicrobial activity varied with the test pathogen and the type of wall material used as protectant during lyophilization. The antimicrobial activity of lyophilized L. plantarum GP gradually decreased upon 2 , 4, and 6 months of storage and was comparable with that of the reference strain GG.

\section{Deconjugation of sodium taurocholate and sodium glycocholate}

Deconjugation ability was determined from the amount of cholic acid released from sodium taurocholate (ST) and sodium glycocholate (SG). Cultures initiated with stored (up to 6 months) lyophilized Lactobacillus cells demonstrated both SG and ST deconjugation ability (Table 3), releasing varying amount of cholic acid $(\mu \mathrm{mol} / \mathrm{mL})$. The range for ST deconjugation was 0.09 $0.54 \mu \mathrm{mol} / \mathrm{mL}$, whereas SG deconjugation was in the range $0.31-1.66 \mu \mathrm{mol} / \mathrm{mL}$. Among the lyophilized cells, GG + lactulose + skim milk released a significant amount of cholic acid $(\mu \mathrm{mol} / \mathrm{mL})$ from SG and ST.

\section{Cholesterol removal assay}

The cultures initiated with the stored lyophilized cells were observed to remove cholesterol to varying extent (44-72\%). Cultures of GP lyophilized with sucrose and GG lyophilized without any wall material showed significantly higher cholesterol removal after $24 \mathrm{~h}$ of incubation in comparison with other cultures from lyophilized cells.

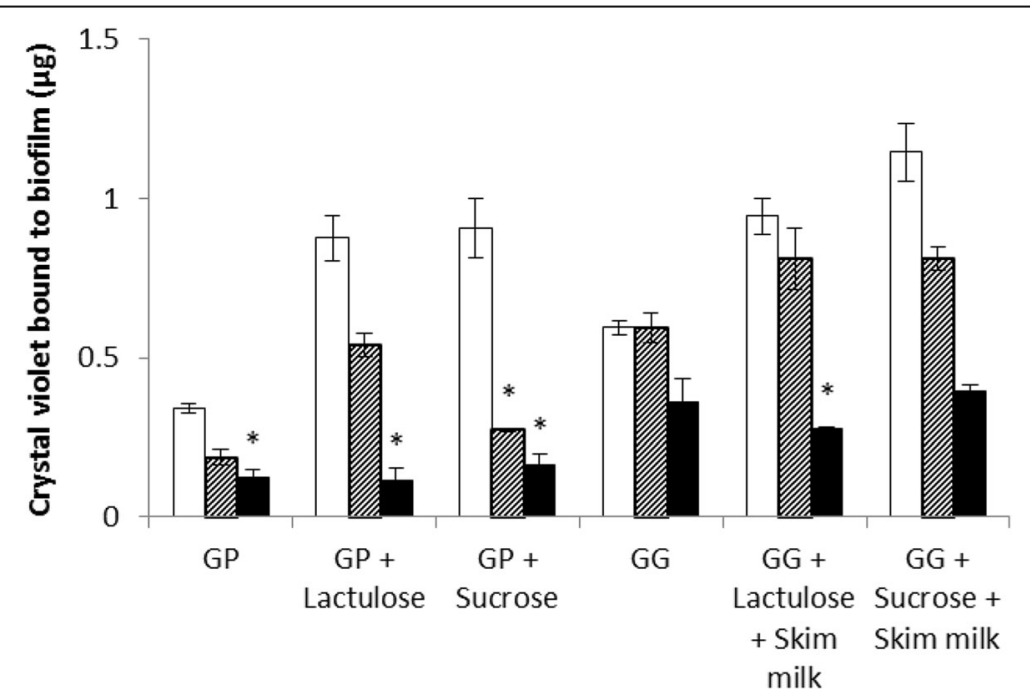

Fig. 4 Crystal violet bound $(\mu \mathrm{g})$ to biofilms produced by L. rhamnosus GG and L. plantarum GP lyophilized cells stored at $8-10{ }^{\circ} \mathrm{C}$ for $2(\square), 4$ (囚), and 6 months $(\mathbf{\square})$. ${ }^{*}$ significantly different $(P<0.05)$ 
Table 2 Antimicrobial activity exerted by lyophilized and stored (for 2, 4, and 6 months) L. rhamnosus GG and L. plantarum GP growing on MRS agar against Gram negative and Gram positive bacteria determined by spot overlay assay

\begin{tabular}{|c|c|c|c|c|c|c|}
\hline \multirow{3}{*}{ Test strains } & \multicolumn{6}{|c|}{ Lactobacillus strains + wall materials } \\
\hline & $\mathrm{GP}$ & GP + lactulose & GP + sucrose & GG & GG + lactulose + skim milk & GG + lactulose + skim milk \\
\hline & \multicolumn{6}{|c|}{ Zone of inhibition (mm) } \\
\hline \multicolumn{7}{|l|}{2 months } \\
\hline E. coli & $25 \pm 0.3$ & $30 \pm 0.4$ & $32 \pm 0.7$ & $25 \pm 0.9$ & $29 \pm 1.4$ & $33 \pm 0.7$ \\
\hline Ent. aerogenes & $19 \pm 2.1$ & $27 \pm 0$ & $28 \pm 0.2$ & $19 \pm 0.4$ & $35 \pm 2.4$ & $38 \pm 0.2$ \\
\hline Sal. typhi & $16 \pm 0.4$ & $24 \pm 0.6$ & $21 \pm 0.7$ & $25 \pm 0.7$ & $33 \pm 0.2$ & $33 \pm 0.4$ \\
\hline Shigella sp.* & $25 \pm 0.7$ & $30 \pm 4.2$ & $31 \pm 0.3$ & $36 \pm 0.7$ & $27 \pm 0.3$ & $27 \pm 0.4$ \\
\hline Pr. vulgaris* & $18 \pm 0.2$ & $23 \pm 1.4$ & $22 \pm 0.0$ & $28 \pm 2.1$ & $33 \pm 2.1$ & $34 \pm 1.1$ \\
\hline K. pneumoniae & $22 \pm 0.3$ & $26 \pm 1.2$ & $31 \pm 0.3$ & $27 \pm 1.7$ & $22 \pm 0.1$ & $2 \pm 0.9$ \\
\hline Staph. aureus & $25 \pm 0.4$ & $22 \pm 0.8$ & $21 \pm 0.6$ & $24 \pm 0.4$ & $26 \pm 0.4$ & $25 \pm 0.6$ \\
\hline Sr. marcescens & $25 \pm 0.6$ & $29 \pm 2.1$ & $33 \pm 0.2$ & $32 \pm 0.2$ & $31 \pm 0.2$ & $27 \pm 1.6$ \\
\hline Ps. aeruginosa & $22 \pm 0.8$ & $24 \pm 1.9$ & $30 \pm 0.6$ & $29 \pm 1.0$ & $26 \pm 0.4$ & $25 \pm 0.2$ \\
\hline B. cereus & $20 \pm 0.2$ & $21 \pm 0.2$ & $21 \pm 0.4$ & $21 \pm 0.4$ & $24 \pm 1.0$ & $24 \pm 1.2$ \\
\hline B. megaterium* & $19 \pm 0.3$ & $26 \pm 2.8$ & $32 \pm 0.5$ & $33 \pm 0.8$ & $34 \pm 0.5$ & $29 \pm 1.2$ \\
\hline B. subtilis & $23 \pm 0.4$ & $24 \pm 0$ & $22 \pm 0.6$ & $23 \pm 1.0$ & $24 \pm 0.6$ & $20 \pm 1.2$ \\
\hline \multicolumn{7}{|l|}{4 months } \\
\hline E. coli & $25 \pm 0.7$ & $25 \pm 0.2$ & $25 \pm 0.5$ & $21 \pm 0.5$ & $20 \pm 0.5$ & $24 \pm 0.7$ \\
\hline Ent. aerogenes & $19 \pm 0.7$ & $19 \pm 0.1$ & $20 \pm 0.0$ & $17 \pm 1.1$ & $23 \pm 0.5$ & $24 \pm 1.2$ \\
\hline Sal. typhi & $10 \pm 0.2$ & $22 \pm 1.4$ & $21 \pm 0.1$ & $16 \pm 4.2$ & $26 \pm 1.4$ & $27 \pm 0.7$ \\
\hline Shigella sp. * & $24 \pm 0.3$ & $29 \pm 0.7$ & $22 \pm 1.0$ & $19 \pm 0.9$ & $27 \pm 2.1$ & $23 \pm 2.1$ \\
\hline Pr. vulgaris* & $15 \pm 0.4$ & $21 \pm 1.4$ & $19 \pm 0.2$ & $17 \pm 0.3$ & $25 \pm 2.1$ & $18 \pm 0.8$ \\
\hline K. pneumoniae* & $20 \pm 0.6$ & $25 \pm 1.2$ & $26 \pm 0.8$ & $20 \pm 1.4$ & $17 \pm 0$ & $19 \pm 1.0$ \\
\hline Staph. aureus & $18 \pm 0.4$ & $18 \pm 0.6$ & $20 \pm 0.2$ & $20 \pm 0.2$ & $19 \pm 0.2$ & $17 \pm 0.8$ \\
\hline Sr. marcescens & $24 \pm 0.4$ & $25 \pm 0.2$ & $26 \pm 0.2$ & $27 \pm 0.2$ & $29 \pm 0.4$ & $25 \pm 1.9$ \\
\hline Ps. aeruginosa & $18 \pm 1.0$ & $20 \pm 1.7$ & $27 \pm 0.8$ & $25 \pm 1.5$ & $23 \pm 0.7$ & $23 \pm 0.7$ \\
\hline B. cereus & $14 \pm 1.4$ & $16 \pm 0.6$ & $16 \pm 0.4$ & $16 \pm 0.2$ & $15 \pm 0.2$ & $17 \pm 0.8$ \\
\hline B. megaterium* & $15 \pm 0.4$ & $21 \pm 3.1$ & $26 \pm 1.0$ & $23 \pm 0.4$ & $23 \pm 0.4$ & $18 \pm 2.5$ \\
\hline B. subtilis & $15 \pm 0.6$ & $18 \pm 1.9$ & $21 \pm 0.8$ & $15 \pm 1.4$ & $13 \pm 0.6$ & $14 \pm 0.2$ \\
\hline \multicolumn{7}{|l|}{6 months } \\
\hline E. coli & $24 \pm 0.4$ & $24 \pm 0.1$ & $25 \pm 1.4$ & $14 \pm 2.1$ & $14 \pm 3.5$ & $20 \pm 2.8$ \\
\hline Ent. aerogenes & $14 \pm 0.4$ & $16 \pm 0.2$ & $15 \pm 0.2$ & $14 \pm 2.8$ & $18 \pm 0.7$ & $18 \pm 2.1$ \\
\hline Sal. typhi & $10 \pm 0.4$ & $20 \pm 2.1$ & $15 \pm 0.3$ & $11 \pm 0.1$ & $17 \pm 2.8$ & $18 \pm 0.8$ \\
\hline Shigella sp.* & $17 \pm 0.6$ & $28 \pm 4.2$ & $22 \pm 0.2$ & $16 \pm 0.4$ & $23 \pm 0.2$ & $16 \pm 0.6$ \\
\hline Pr. vulgaris* & $13 \pm 0.6$ & $14 \pm 2.1$ & $15 \pm 1.0$ & $17 \pm 4.9$ & $16 \pm 1.1$ & $16 \pm 2.8$ \\
\hline K. pneumoniae & $15 \pm 0.8$ & $18 \pm 2.1$ & $20 \pm 1.0$ & $16 \pm 0.8$ & $15 \pm 0.4$ & $16 \pm 0.2$ \\
\hline Staph. aureus & $12 \pm 0.5$ & $14 \pm 1.2$ & $17 \pm 0.3$ & $15 \pm 0.3$ & $13 \pm 0.1$ & $12 \pm 0.1$ \\
\hline Sr. marcescens & $16 \pm 0.6$ & $21 \pm 1.4$ & $23 \pm 0.6$ & $22 \pm 0.2$ & $22 \pm 0.4$ & $18 \pm 1.0$ \\
\hline Ps. aeruginosa & $15 \pm 0.6$ & $17 \pm 0.2$ & $20 \pm 0.8$ & $19 \pm 1.2$ & $18 \pm 0.8$ & $17 \pm 1.2$ \\
\hline B. cereus & $12 \pm 1.0$ & $11 \pm 0.4$ & $11 \pm 0.4$ & $11 \pm 0.4$ & $13 \pm 0.4$ & $15 \pm 0.4$ \\
\hline B. megaterium* & $13 \pm 0.6$ & $17 \pm 0.8$ & $22 \pm 1.2$ & $20 \pm 2.1$ & $16 \pm 0.6$ & $16 \pm 0.6$ \\
\hline B. subtilis & $13 \pm 0.8$ & $17 \pm 0.5$ & $19 \pm 0.1$ & $15 \pm 1.5$ & $11 \pm 0$ & $10 \pm 0.1$ \\
\hline
\end{tabular}


Table $3 \beta$-galactosidase, bile salt hydrolase, percentage of cholesterol reduction, and DPPH radical scavenging activities of lyophilized L. rhamnosus GG and L. plantarum GP stored for 6 months

\begin{tabular}{|c|c|c|c|c|c|}
\hline \multirow{2}{*}{$\begin{array}{l}\text { Lactobacillus } \\
\text { Strains + wall materials }\end{array}$} & \multirow{2}{*}{$\begin{array}{l}\beta \text {-galactosidase } \\
\text { activity } \\
\text { (Miller's unit) }\end{array}$} & \multicolumn{2}{|c|}{ Bile salt hydrolase activity (cholic acid releases) } & \multirow{2}{*}{$\begin{array}{l}\text { Cholesterol } \\
\text { removal } \\
(\%)\end{array}$} & \multirow{2}{*}{$\begin{array}{l}\text { DPPH radical } \\
\text { scavenging activity } \\
(\%)\end{array}$} \\
\hline & & $\mathrm{SG}(\mu \mathrm{mol} / \mathrm{mL})$ & $\mathrm{ST}(\mu \mathrm{mol} / \mathrm{mL})$ & & \\
\hline GP & $313 \pm 0.2^{*}$ & $0.33 \pm 0.08$ & $0.35 \pm 0.02$ & $44 \pm 1.9$ & $58 \pm 0.5$ \\
\hline $\mathrm{GP}+$ lactulose & $321 \pm 0.3^{*}$ & $0.74 \pm 0.13$ & $0.46 \pm 0.09$ & $67 \pm 2.7$ & $62 \pm 0.8$ \\
\hline $\mathrm{GP}+$ sucrose & $278 \pm 0.8^{*}$ & $0.31 \pm 0.14$ & $0.14 \pm 0.03$ & $60 \pm 1.5$ & $77 \pm 1.2^{*}$ \\
\hline GG & $54 \pm 0.8$ & $0.83 \pm 0.32$ & $0.13 \pm 0.01$ & $58 \pm 1.0$ & $73 \pm 0.9^{*}$ \\
\hline GG + lactulose + skim milk & $80 \pm 0.3$ & $1.66 \pm 0.04^{*}$ & $0.54 \pm 0.11$ & $72 \pm 4.6^{*}$ & $53 \pm 0.3$ \\
\hline GG + sucrose + skim milk & $143 \pm 0.5$ & $0.66 \pm 0.2$ & $0.09 \pm 0.01$ & $59 \pm 3.0$ & $57 \pm 0.3$ \\
\hline
\end{tabular}

*values significantly different $(P<0.05)$

\section{$\beta$-galactosidase activity}

Cultures of L. plantarum GP and L. rhamnosus GG initiated by lyophilized cells stored for 6 months produced $\beta$-galactosidase activity ( $\geq 54$ Miller's unit) in the presence of lactose in MRS medium (Table 3). Cultures initiated with GP cells lyophilized with lactulose as wall material produced significantly higher $\beta$-galactosidase activity (321 Miller's unit) than the free GP cells grown in MRS with lactose (Shekh et al. 2016).

\section{DPPH scavenging activity}

L. plantarum GP lyophilized with sucrose exhibited strong DPPH scavenging activity $(77 \pm 1.2 \%)$ similar to the reference strain L. rhamnosus GG (73 $\pm 0.9 \%)$, whereas the scavenging ability of the GP and GG cells lyophilized in the presence of other wall materials was considerably lower (Table 3).

\section{GABA production}

L. plantarum GP with and without wall material produced GABA which was observed as intense spots on TLC plates.

\section{Discussion}

A probiotic microorganism used in formulations has to fulfill certain selection criteria for acceptance in the final probiotic product. These include probiotic efficacy, nonpathogenicity, and survival for prolonged period during processing, storage, and gastrointestinal tract transit. Prebiotics, skim milk, and sucrose were used in various combinations to enhance the survival of Lactobacillus plantarum GP cells during lyophilization and storage. The lyophilized vials without any wall material, included as control, showed significant reduction in viability after lyophilization. The survival rate during 6 months of storage was also poor in cells lyophilized without any wall material. Among the different combinations of cryoprotectants, GP retained significant viability (\%) with lactulose and skim milk, whereas in the case of GG it was with lactulose + skim milk and sucrose + skim milk. The prolonged survival is due to the ability of a strain to ferment particular prebiotic and sugar and use them as fermentable carbon sources (Slavin 2013; McLaughlin et al. 2015). Lactose, lactose + skim milk, and ascorbic acids exerted similar cryoprotective effects during lyophilization (Zárate and Nader-Macias 2006; Montel Mendoza et al. 2014).

The functional and health beneficial aspects of probiotics may include survival, adhesion, and colonization during gastrointestinal tract transit, antimicrobial activity, and production of enzymes like $\beta$-galactosidase, bile salt hydrolase (BSH), and glutamate decarboxylase. We evaluated the survival of Lactobacilli after lyophilization in the presence of simulated GIT conditions and antimicrobial activity against food spoilage and GIT pathogens. The probiotics present in food products encounter various environmental conditions upon ingestion by the host and during GIT transit. Our experimental data substantiate the viability of lyophilized cells of $L$. plantarum GP and L. rhamnosus GG through a sequential exposure to simulated gastric and intestinal conditions. GP and GG cells lyophilized with wall materials had significantly higher survival rate and shelf life than the cells lyophilized without any wall material. Lactulose acts as a protectant and metabolized into low molecular weight acids (German et al. 2008) by Lactobacilli thereby stimulating the growth of acid-tolerant Lactobacilli (Collins et al. 2017). In this study, lyophilization of cells with lactulose significantly improved the viability of GP during the stress conditions of human GIT as compared with sucrose where survival of cells decreased upon storage. Rajam and Anandharamakrishnan (2015) reported the protective effects of fructooligosaccharides + whey protein isolate during simulated transit of L. plantarum.

The adhesion to mammalian epithelial cells is an essential attribute for probiotic bacteria in functional foods to survive and colonize the gastrointestinal tract to exert claimed probiotic benefits. L. plantarum GP and $L$. rhamnosus GG displayed a significant number of $\log$ cfu/well adhered to mucus layer during storage of 6 
months. The wall materials provide protection to the lyophilized cells of Lactobacilli during freeze drying and storage that resulted in significant mucin adhesion capacity. Zárate and Nader-Macias (2006) reported similar restored mucin adhesion capacity of lyophilized cells of Lactobacilli after the first subculturing. Prebiotics and sucrose also improve the biofilm formation capacity of cultures from lyophilized cells by altering their cell surface properties according to Lebeer et al. (2007), where biofilm formation capacity of GG increased by 1.5 fold in the presence of inulin.

The microbial contamination of food can have many undesirable consequences ranging from spoilage to food-borne illness. The use of LAB with potential antimicrobial activity is a promising alternative treatment for such problems. Lactobacillus strains exhibit broad spectrum antimicrobial activity against Gram positive and Gram negative major food spoiling organisms and gastrointestinal pathogens. Lactobacillus strains show varying degree of strain specific antibacterial activity against tested pathogens. Strain specific and growth phase dependent production of antimicrobial substances has also been reported previously (Zárate and NaderMacias 2006; Boricha et al. 2019). Lactobacillus strains freeze dried with lactose, skim milk, and ascorbic acid exerted antimicrobial action as the antimicrobials production was not affected by lyophilization (Zárate and Nader-Macias 2006). Lyophilized vials of L. plantarum GP stored up to 6 months retained antimicrobial activity against selected food spoiling organisms and human GIT pathogens. The lyophilized cells of L. plantarum GP can be incorporated in a food product to prevent food spoilage and infection by the opportunistic GIT pathogens.

The elevated levels of serum cholesterol are considered as one of the major factors associated with coronary heart diseases (Prema et al. 2010) because of improper food habits. Therefore, maintaining lower serum cholesterol is required to prevent cardiovascular diseases. Diets with probiotic strains are one of the promising strategies for controlling serum cholesterol level. BSH produced by Lactobacilli catalyses the hydrolysis of glycine- or taurine-conjugated bile salts into the amino acids and free bile acids (Corzo and Gilliland 1999). Deconjugated bile salts are less soluble than conjugated bile salts, resulting in lower absorption in the intestinal lumen, leading to their elimination in the feces. Since free bile acids are extracted from the body, the synthesis of new bile salts from cholesterol can reduce the total cholesterol concentration in the body. Lactobacillus GG and GP mediated deconjugation of bile salts was significantly higher $(0.09-1.66 \mu \mathrm{mol} / \mathrm{ml}$ cholic acid) and therefore in recent years, interest has increased to use bile salt hydrolysis to influence the cholesterol metabolism of humans. Moreover, cultures initiated with lyophilized cells efficiently removed cholesterol from the medium (44-72\%). Miremadi et al. (2014) reported a similar cholesterol removal activity by normally grown cells of Lactobacilli and Bifidobacteria. Several mechanisms proposed include assimilation of cholesterol (Pereira and Gibson 2002; Wang et al. 2014), surface binding (Liong and Shah 2005), incorporation into cellular membranes (Lye et al. 2010a), co-precipitation with deconjugated bile (Liong and Shah 2006), enzymatic deconjugation of bile acids by BSH (Lambert et al. 2008), conversion of cholesterol into coprostanol (Lye et al. 2010b), and production of short-chain fatty acids by probiotics (De Preter et al. 2007).

The deficiency of $\beta$-galactosidase is the cause of lactose intolerance as this enzyme hydrolyses lactose into galactose and glucose. Most fermented foods, especially fermented milk, improve lactose digestion. The probiotic organisms utilize lactose and convert it into short-chain fatty acid which is beneficial for the host by preventing colonic disease (Pessione et al. 2015). L. plantarum GP produced a significant amount of $\beta$-galactosidase in the medium with lactose even after lyophilization. Thus, the products fermented with $\beta$-galactosidase producer GP serve as a source for $\beta$-galactosidase and play a vital role for the treatment of lactose intolerance.

Increasing scientific evidence suggests that oxidative stress is involved in the pathogenesis of various disorders and diseases, such as alcohol-induced liver injury, nonalcoholic fatty liver disease, aging, and cancer (Beckman and Ames 1998; Cederbaum et al. 2009; Nobili et al. 2010; $\mathrm{Yu}$ and Kim 2014). Oxidative stress is a result of an imbalance between the production and elimination of reactive oxygen species (ROS) and free radicals, which are primarily removed by the endogenous antioxidant defense system (Halliwell and Gutteridge 1985). Consumption of antioxidants, which can quench free radicals and ROS, is beneficial to human health. Synthetic antioxidants are effective in slowing oxidation but pose concerns in regard to the safety and toxicity of the antioxidants (Sies 1993; Velioglu et al. 1998). DPPH is usually used to determine the proton-radical scavenging action of the antioxidant. DPPH possesses a proton free radical and shows a characteristic absorption at $517 \mathrm{~nm}$ wavelength. When DPPH was encountered with protonradical scavengers, the purple color of DPPH solution faded rapidly. Lactobacillus strains have a role as antioxidative agents by scavenging different free radicals like hydroxyl, 2,2-azinobis-(3-ethylbenzothiazoline-6-sulfonic acid), $\mathrm{Fe}^{2+}$, and superoxide anion radicals (Shekh et al. 2016, unpublished data).

GABA is a non-protein amino acid produced by $\alpha$ decarboxylation of glutamate by the action of enzyme glutamate decarboxylase. It acts as a major inhibitory 
neurotransmitter in the mammalian central nervous system (Schousboe and Waagepetersen 2007), having hypotensive, tranquilizing, and diuretic effects, and can prevent diabetes (Hayakawa et al. 2004; $\mathrm{Li}$ and Cao 2010). Therefore, GABA producing vials of $L$. plantarum GP can be included in fermented foods to acquire relief from the abovementioned conditions.

\section{Conclusion}

Lactobacillus plantarum GP possesses significant viability during the storage and exposure to simulated orogastro-intestinal fluids when formulated with the wall material lactulose, sucrose, and skim milk. The lyophilized cells of the strain GP display promising antimicrobial action towards food spoilage and pathogenic organisms. These synbiotics are functional probiotics having ability to adhere mucin layer, produce biofilms, and improve in lactose intolerance and hypercholesterolemia. Additionally, these synbiotics act as antioxidants and produce BSH and GABA up to 6 months of storage. Therefore, synbiotics prepared by lyophilization can be used to formulate probiotic food products to improve overall human health.

\section{Acknowledgements}

We acknowledge fellowship to Ms. Satyamitra Shekh by University Grants Commission, New Delhi, India (BSR Research Fellowship for Meritorious

Students in Science).

\section{Authors' contributions}

All the authors have read and approved the final manuscript.

\section{Funding}

N/A

\section{Ethics approval and consent to participate}

N/A

\section{Consent for publication}

N/A

\section{Competing interests}

The authors declare that they have no competing interests.

\section{Author details}

${ }^{1}$ Navyug B.Ed. and B.Sc. College, Virpar, Morbi 363641, India. ${ }^{2}$ Department of Biosciences, Saurashtra University, Rajkot 360005, India.

Received: 13 August 2019 Accepted: 29 January 2020

Published online: 09 March 2020

\section{References}

Anal AK, Singh H (2007) Recent advances in microencapsulation of probiotics for industrial applications and targeted delivery. Trends Food Sci Technol 18(5): 240-251

Beckman KB, Ames BN (1998) The free radical theory of aging matures. Physiol Rev 78(2):547-581

Boricha AA, Shekh SL, Pithva SP, Ambalam PS, Vyas BRM (2019) In vitro evaluation of probiotic properties of Lactobacillus species of food and human origin. LWT 106:201-208

Burgain J, Gaiani C, Linder M, Scher J (2011) Encapsulation of probiotic living cells: from laboratory scale to industrial applications. J Food Eng 104(4):467-483

Carvalho AS, Silva J, Ho P. Teixeira PM, Malcata EX, Gibbs P (2004) Effects of various sugars added to growth and dryingmedia upon thermotolerance and survival throughout storage of freeze-dried Lactobacillus delbrueckii ssp. bulgaricus. Biotechnol Progress 20:248-254

Cederbaum Al, Lu Y, Wu D (2009) Role of oxidative stress in alcohol-induced liver injury. Arch Toxicol 83(6):519-548

Chavan M, Gat Y, Harmalkar M, Waghmare R (2018) Development of non-dairy fermented probiotic drink based on germinated and ungerminated cereals and legume. Food Sci Technol Zurich 91(1):339-344

Collins SL, McMillan A, Seney S, van der Veer C, Kort R, Sumarah MW, Reid G (2017) Evaluation of lactitol, lactulose, raffinose, and oligofructose for maintenance of a Lactobacillus-dominated vaginal microbiota establishes a promising prebiotic candidate. Appl Environ Microbiol:02200

Corzo G, Gilliland SE (1999) Bile salt hydrolase activity of three strains of Lactobacillus acidophilus 1. J Dairy Sci 82(3):472-480

De Preter V, Vanhoutte T, Huys G, Swings J, De Vuyst L, Rutgeerts P, Verbeke K (2007) Effects of Lactobacillus casei Shirota, Bifidobacterium breve, and oligofructose-enriched inulin on colonic nitrogen-protein metabolism in healthy humans. Am J Physiol-Gastrointest Liver Physiol 292(1):G358-G368

de Vos P, Faas MM, Spasojevic M, Sikkema J (2010) Encapsulation for preservation of functionality and targeted delivery of bioactive food components. Int Dairy J 20(4):292-302

Dhanani AS, Bagchi T (2013) The expression of adhesin EF-Tu in response to mucin and its role in Lactobacillus adhesion and competitive inhibition of enteropathogens to mucin. J Appl Microbiol 115:546-554

EAFUS, 1998. Everything added in foods in the United States. http://www. accessdata.fda.gov/scripts/fcn/fcnnavigation.cfm?rpt5eafuslisting.

Fonseca F, Cenard S, Passot S (2015) Freeze-drying of lactic acid bacteria. Methods Mol Biol 1257:477-488

German AJ, Maddison JE, Guilford G (2008) Gastrointestinal drugs. Small Animal Clinical Pharmacology. Saunders, Edinburgh, pp 469-497

Gibson GR (1999) Dietary modulation of the human gut microflora using the prebiotics oligofructose and inulin. J Nutr 129(7):1438s-1441s

Gilliland SE, Nelson CR, Maxwell C (1985) Assimilation of cholesterol by Lactobacillus acidophilus. Appl Environ Microbiol 49(2):377-381

Gonzalez NJ, Adhikari K, Sancho-Madriz MF (2011) Sensory characteristics of peach-flavored yogurt drinks containing prebiotics and synbiotics. LWT Food Sci Technol 44(1):158-163

Granato D, Nazzaro F, Pimentel TC, Esmerino EA, \& da Cruzb AG. (2015). Probiotic food development: an updated review based on technological advancement.

Halliwell B, Gutteridge J (1985) Free radicals in biology and medicine. Oxford Clarendon Press, pp 23-30

Hayakawa K, Kimura M, Kasaha K, Matsumoto K, Sansawa H, Yamori Y (2004) Effect of a $\gamma$-aminobutyric acid-enriched dairy product on the blood pressure of spontaneously hypertensive and normotensive Wistar-Kyoto rats. Br J Nutr 92(3):411-417

Heidebach T, Först P, Kulozik U (2012) Microencapsulation of probiotic cells for food applications. Crit Rev Food Sci Nutr 52(4):291-311

Hill C, Guarner F, Reid G, Gibson GR, Merenstein DJ, Pot B et al (2014) Expert consensus document: the International Scientific Association for Probiotics and Prebiotics consensus statement on the scope and appropriate use of the term probiotic. Nat Rev Gastroenterol Hepato 11(8):506-514

Irvin JL, Johnston CG, Kopala J (1944) A photometric method for the determination of cholates in bile and blood. J Biol Chem 153(2):439-457

Jankovic I, Sybesma W, Phothirath P, Ananta E, Mercenier A (2010) Application of probiotics in food products - challenges and new approaches. Curr Opin Biotechnol 21(2):175-181

Kaplan H, Hutkins RW (2000) Fermentation of fructooligosaccharides by lactic acid bacteria and bifidobacteria. Appl Environ Microbiol 66(6):2682-2684

Konar N, Palabiyik I, Toker OS, Polat DG, Kelleci E, Pirouzian HR et al (2018) Conventional and sugar-free probiotic white chocolate: effect of inulin DP on various quality properties and viability of probiotics. J Funct Foods 43:206-213

Lambert JM, Bongers RS, de Vos WM, Kleerebezem M (2008) Functional analysis of four bile salt hydrolase and penicillin acylase family members in Lactobacillus plantarum WCFS1. Appl Environ Microbiol 74(15):4719-4726

Lebeer S, Verhoeven TL, Vélez MP, Vanderleyden J, De Keersmaecker SC (2007) Biofilm formation by the probiotic Lactobacillus rhamnosus GG: impact of environmental and genetic factors. Appl Environ Microbiol.

Lee BJ, Kim JS, Kang YM, Lim JH, Kim YM, Lee MS et al (2010) Antioxidant activity and $\gamma$-aminobutyric acid (GABA) content in sea tangle fermented by Lactobacillus brevis BJ20 isolated from traditional fermented foods. Food Chem 122(1):271-276 
Li H, Cao Y (2010) Lactic acid bacterial cell factories for gamma-aminobutyric acid. Amino Acids 39(5):1107-1116

Liong MT, Shah NP (2005) Acid and bile tolerance and cholesterol removal ability of lactobacilli strains. J Dairy Sci 88(1):55-66

Liong MT, Shah NP (2006) Effects of a Lactobacillus casei synbiotic on serum lipoprotein, intestinal microflora, and organic acids in rats. J Dairy Sci 89(5): 1390-1399

Lye HS, Rahmat-Ali GR, Liong MT (2010a) Mechanisms of cholesterol removal by lactobacilli under conditions that mimic the human gastrointestinal tract. Int Dairy J 20(3):169-175

Lye HS, Rusul G, Liong MT (2010b) Removal of cholesterol by lactobacilli via incorporation and conversion to coprostanol. J Dairy Sci 93(4):1383-1392

Malik KA (1988) A new freeze-drying method for the preservation of nitrogenfixing and other fragile bacteria. J Microbiol Methods 8(5):259-271

McLaughlin HP, Motherway MO, Lakshminarayanan B, Stanton C, Ross RP, Brulc J et al (2015) Carbohydrate catabolic diversity of bifidobacteria and lactobacilli of human origin. Int J Food Microbiol 203:109-121

Meng XC, Stanton C, Fitzgerald GF, Daly C, Ross RP (2008) Anhydrobiotics: the challenges of drying probiotic cultures. Food Chem 106:1406-1416

Miremadi F, Ayyash M, Sherkat F, Stojanovska L (2014) Cholesterol reduction mechanisms and fatty acid composition of cellular membranes of probiotic Lactobacilli and Bifidobacteria. J Funct Foods 9:295-305

Montel Mendoza G, Pasteris SE, Otero MC, Fatima Nader-Macías ME (2014) Survival and beneficial properties of lactic acid bacteria from raniculture subjected to freeze-drying and storage. J Appl Microbiol 116(1):157-166

Nilsson HO, Fiutka A, Moran A, Ljungh Å, \& Wadstrom T. (2008). Biofilm formation and survival of $\mathrm{H}$-pylori and enterohepatic Helicobacter species in the presence of native porcine bile and bile salts. In XXI International Workshop on Helicobacter and Related Bacteria in Chronic Digestive Inflammation and Gastric Cancer, 13(5), 410-410 Wiley-Blackwell.

Nobili V, Parola M, Alisi A, Marra F, Piemonte F, Mombello C et al (2010) Oxidative stress parameters in paediatric non-alcoholic fatty liver disease. Int J Mol Med 26(4):471

Pavunc AL, Beganović J, Kos B, Buneta ANA, Beluhan S, Šušković J (2011) Influence of microencapsulation and transglutaminase on viability of probiotic strain Lactobacillus helveticus M92 and consistency of set yoghurt. Int J Dairy Technol 64(2):254-261

Pereira DI, Gibson GR (2002) Cholesterol assimilation by lactic acid bacteria and bifidobacteria isolated from the human gut. Appl Environ Microbiol 68(9): 4689-4693

Pessione A, Bianco GL, Mangiapane E, Cirrincione S, Pessione E (2015) Characterization of potentially probiotic lactic acid bacteria isolated from olives: evaluation of short chain fatty acids production and analysis of the extracellular proteome. Food Res Int 67:247-254

Pithva S, Shekh S, Dave J, Vyas BRM (2014) Probiotic attributes of autochthonous Lactobacillus rhamnosus strains of human origin. Appl Biochem Biotechnol 173(1):259-277

Prema P, Smila D, Palavesam A, Immanuel G (2010) Production and characterization of an antifungal compound (3-phenyllactic acid) produced by Lactobacillus plantarum strain. Food Bioproc Tech 3(3):379-386

Rajam R, Anandharamakrishnan C (2015) Microencapsulation of Lactobacillus plantarum (MTCC 5422) with fructooligosaccharide as wall material by spray drying. LWT Food Sci Technol 60(2):773-780

Rajam R, Karthik P, Parthasarathi S, Joseph GS, Anandharamakrishnan C (2012) Effect of whey protein-alginate wall systems on survival of microencapsulated Lactobacillus plantarum in simulated gastrointestinal conditions. J Funct Foods 4(4):891-898

Rodrigues D, Rocha-Santos TA, Pereira Cl, Gomes AM, Malcata FX, Freitas AC (2011) The potential effect of FOS and inulin upon probiotic bacterium performance in curdled milk matrices. LWT Food Sci Technol 44(1):100-108

Schillinger U, Lucke FK (1989) Antibacterial activity of Lactobacillus sake isolated from meat. Appl Environ Microbiol 55:1901-1906

Schousboe A, Waagepetersen HS (2007) GABA: homeostatic and pharmacological aspects. Prog Brain Res 160:9-19

Shekh SL, Dave JM, Vyas BRM (2016) Characterization of Lactobacillus plantarum strains for functionality, safety and $\gamma$-amino butyric acid production. LWT Food Sci Technol 74:234-241

Shimada K, Fujikawa K, Yahara K, Nakamura T (1992) Antioxidative properties of xanthan on the autoxidation of soybean oil in cyclodextrin emulsion. J Agric Food Chem 40(6):945-948

Sies H (1993) Strategies of antioxidant defense. Eur J Biochem 215:213-219
Slavin J (2013) Fiber and prebiotics: mechanisms and health benefits. Nutrients 5(4):1417-1435

Velioglu YS, Mazza G, Gao L, Oomah BD (1998) Antioxidant activity and total phenolics in selected fruits, vegetables, and grain products. J Agric Food Chem 46(10):4113-4117

Walker DK, Gilliland SE (1993) Relationships among bile tolerance, bile salt deconjugation, and assimilation of cholesterol by Lactobacillus acidophilus 1. J Dairy Sci 76(4):956-961

Wang SC, Chang CK, Chan SC, Shieh JS, Chiu CK, Duh PD (2014) Effects of lactic acid bacteria isolated from fermented mustard on lowering cholesterol. Asian Pac J Trop Biomed 4(7):523-528

Watnick PI, Kolter R (1999) Steps in the development of a Vibrio cholerae El Tor biofilm. Mol Microbiol 34(3):586-595

World Health Organization (2006) Probiotics in food: health and nutritional properties and guidelines for evaluation. Food and Agriculture Organization of the United Nations, Rome

Yu JH, Kim H (2014) Oxidative stress and cytokines in the pathogenesis of pancreatic cancer. J Cancer Prev 19(2):97-102

Zárate G, Nader-Macias ME (2006) Viability and biological properties of probiotic vaginal lactobacilli after lyophilization and refrigerated storage into gelatin capsules. Process Biochem 41(8):1779-1785

\section{Publisher's Note}

Springer Nature remains neutral with regard to jurisdictional claims in published maps and institutional affiliations.
Ready to submit your research? Choose BMC and benefit from:

- fast, convenient online submission

- thorough peer review by experienced researchers in your field

- rapid publication on acceptance

- support for research data, including large and complex data types

- gold Open Access which fosters wider collaboration and increased citations

- maximum visibility for your research: over $100 \mathrm{M}$ website views per year

At $\mathrm{BMC}$, research is always in progress.

Learn more biomedcentral.com/submissions 